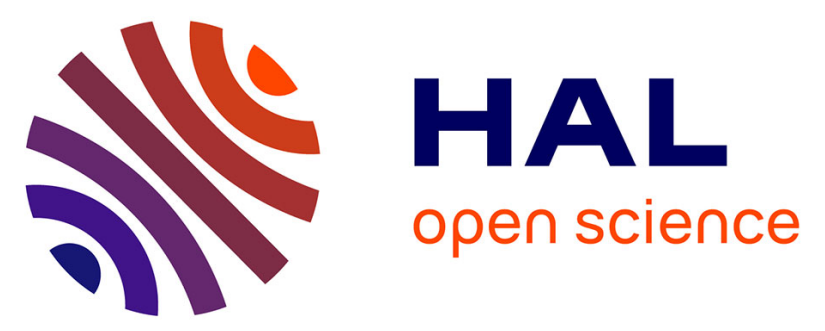

\title{
Systematic utilization of layered double hydroxide nanosheets for effective removal of methyl orange from an aqueous system by $\pi-\pi$ stacking-induced nanoconfinement
}

\author{
Su-Joung Ko, Tetsuo Yamaguchi, Fabrice Salles, Jae-Min Oh
}

\section{To cite this version:}

Su-Joung Ko, Tetsuo Yamaguchi, Fabrice Salles, Jae-Min Oh. Systematic utilization of layered double hydroxide nanosheets for effective removal of methyl orange from an aqueous system by $\pi-\pi$ stacking-induced nanoconfinement. Journal of Environmental Management, 2021, 277, pp.111455. 10.1016/j.jenvman.2020.111455 . hal-02970787

\section{HAL Id: hal-02970787 \\ https://hal.science/hal-02970787}

Submitted on 18 Nov 2020

HAL is a multi-disciplinary open access archive for the deposit and dissemination of scientific research documents, whether they are published or not. The documents may come from teaching and research institutions in France or abroad, or from public or private research centers.
L'archive ouverte pluridisciplinaire HAL, est destinée au dépôt et à la diffusion de documents scientifiques de niveau recherche, publiés ou non, émanant des établissements d'enseignement et de recherche français ou étrangers, des laboratoires publics ou privés. 
1 Title: Systematic utilization of layered double hydroxide nanosheets for effective removal of methyl

2 3 orange from aqueous system by $\pi$ - $\pi$ stacking induced nanoconfinement

\section{Su-Joung $\mathrm{Ko}^{1 \S}$, Tetsuo Yamaguchi ${ }^{1 \S}$, Fabrice Salles ${ }^{2 *}$, Jae-Min $\mathrm{Oh}^{1 *}$}

${ }^{1}$ Department of Energy and Materials Engineering, Dongguk University-Seoul, Seoul 04620, Korea ${ }^{2}$ ICGM, Univ. Montpellier, CNRS, ENSCM, Montpellier, France

e-mail: J.-M. Oh jaemin.oh@dongguk.edu

F. Salles fabrice.salles@umontpellier.fr

§These authors equally contributed to the work.

\section{Abstract}

Systematic utilization of carbonated Mg-Al layered double hydroxide (LDH) nanosheets on methyl orange removal was investigated with a respect to particle dimension. LDHs with smallest dimension were synthesized carefully to have a small lateral size as well as high dispersibility. The other particles with medium and large sizes were prepared by hydrothermal treatment and urea hydrolysis to have larger size and higher crystallinity. According to kinetics and isotherm analyses, the smallest sized LDH showed effective adsorption of methyl orange (1250 mg/g-LDH) which was remarkable higher than the other LDHs with the larger lateral sizes. Compared with the larger lateral sized LDHs, the small sized ones were verified to utilize all the accessible adsorption sites of the nanosheets generating nanoconfinement of the methyl orange molecules. Transmission electron microscopy (TEM) and powder X-ray diffraction (PXRD) patterns definitely indicated that the LDHs with $\sim 40 \mathrm{~nm}$ of the lateral dimension could fully utilize the interlayer nanospace of the LDH. MonteCarlo simulation suggested the intercalated methyl orange could be stabilized not only through electrostatic interaction with the LDH layer but also by $\pi$ - $\pi$ stacking between the methyl orange molecules, which is thought to be the driving force to replace carbonate anion.

\section{Keywords}

Cationic dye removal, LDH, Monte-Carlo simulation, size effect, intercalation

\section{Introduction}

Water pollution is one of most serious global problems. In order to address the problem, removal of the pollutant is a secure way and thus environmental friendly adsorbent is important. Various adsorbents have been developed to specifically remove cations (Delkash et al., 2015; Leodopoulos et al., 2014; Liu and Zhang, 2007; Malamis and Katsou, 2013; Mohanty et al., 2006b, 2006a; Srividya and Mohanty, 2009; Teepakakorn et al., 2019; Yamaguchi and Ogawa, 2020), anions 
1 (Khan et al., 2013; Kim et al., 2014; Teepakakorn et al., 2019), neutral molecules(Aznar et al., 2016;

2 Gomez et al., 2018; Khan et al., 2013; Malamis and Katsou, 2013; Phuekphong et al., 2020;

3 Teepakakorn et al., 2019; Yamaguchi and Ogawa, 2020; Zhang et al., 2017), polymers (Pilavtepe et

4 al., 2018; Sun et al., 2011) and etc. Among them, layered double hydroxide (LDH), also known as

5 anionic clay, has attracted special interests as anion scavenger (Choy et al., 2007; Goh et al., 2008;

6 Kim et al., 2014; Leroux and Taviot-Gueho, 2005; Miyata, 1983; Omwoma et al., 2014). Generally,

$7 \quad$ LDHs are composed of positively charged nanolayers $\left(\mathrm{M}(\mathrm{II})_{1-\mathrm{x}} \mathrm{M}(\mathrm{III})_{\mathrm{x}}(\mathrm{OH})_{2}{ }^{\mathrm{x}+} ; \mathrm{M}(\mathrm{II}), \mathrm{M}(\mathrm{III})\right.$ : divalent

8 and trivalent metal cations, $0.2<\mathrm{x}<0.4)$ and charge-compensating interlayer anions. Various types

9 of divalent ( $\mathrm{Mg}, \mathrm{Mn}, \mathrm{Fe}, \mathrm{Co}, \mathrm{Ni}, \mathrm{Cu}$ and $\mathrm{Zn}$ ) and trivalent (Al, $\mathrm{Mn}, \mathrm{Fe}, \mathrm{Co}, \mathrm{Ni}, \mathrm{Cr}$ and $\mathrm{Ga}$ ) metal

10 cations are accepted for the nanosheets (Rives, 2001). The interlayer anions, for example carbonate,

11 halogens, sulfate, nitrate and so on can be directly accommodated (Goh et al., 2008) by using

12 corresponding metal salts during synthesis. The LDHs have strong points as anionic scavenger.

13 First, the LDHs can be synthesized in relatively mild conditions (e.g. at room temperature in water)

14 with biocompatible metal cations (Wijitwongwan et al., 2019). Second, various kinds of organic

15 anions can be incorporated between the nanosheets through ion-exchange reaction (Leroux and Taviot-

16 Gueho, 2005; Wang and Hare, 2012); and high theoretical specific surface area of single LDH

17 nanosheet $\left(\sim 2,000 \mathrm{~m}^{2} \mathrm{~g}^{-1}\right)$ calculated from unit cell of the LDH layer enables accommodation of a

18 large amount of the anions. Third, the LDHs can be collected from aqueous systems by simple

19 filtration or sedimentation. Fourth, dye selectivity based on molecular configuration and size is

20 expected from the report of clays (Atun et al., 2009; Bée et al., 2017; Smith and Jaffé, 1994), although

21 the anion selectivity for LDH is almost limited in inorganic cations so far (He et al., 2010; Li et al., 22 2017).

In spite of above-mentioned advantages, the LDHs have some drawbacks as practical anionic adsorbents. Carbonate anion is extremely stable between the LDH layers. Thus, it is easy to prepare carbonated LDHs but their interlayer space cannot be fully exploited as adsorbent site due to the low ion-exchange susceptibility (Choy et al., 2007; Kim et al., 2014; Oh et al., 2009), which is a reason of the smaller empirical surface area than the theoretical one. On the other hand, exchanged LDHs, such as nitrated one, can effectively adsorb anions through ion-exchange, but the production of the nitrated LDHs requires much energy and the release nitrate after anion removal can induce secondary pollution by eutrophication. In this regard, it is strongly required to find a way to utilize as many adsorption sites of the carbonated LDHs as possible in order to obtain environmental-friendly and economical adsorbent.

There have been many reports on LDH based anion adsorbent. As it is thought that the LDHs form laminated particles in aqueous systems, maximum utilization of the laminated structure expects effective removal of the anionic pollutants (Cheng et al., 2019; Zhu et al., 2014). In previous study, the adsorption of methyl orange (MO) onto carboxylate-CuZn-LDH (476 mg/g-LDH) (Zhu et al., 
2014), $\mathrm{Fe}_{2} \mathrm{O}_{3}$ doped nitrate-MgAl-LDH (577 mg/g-LDH) (Cheng et al., 2019) and Cl-Co $\mathrm{Co}_{4} \mathrm{Al}-\mathrm{LDH}$ (801 $\mathrm{mg} / \mathrm{g}-\mathrm{LDH})$ (Chen et al., 2019) was reported. In these cases, the adsorption followed the Langmuir isotherm, indicating that the intercalation of MO into the interlayer nanospace did not occur effectively despite of exchangeable carboxylate, nitrate and chloride. In order to solve the problem, ion-exchange behavior of the LDHs with respect to their physicochemical properties should be understood before adsorbent design. Sufficient comprehension would even enable the utility of the carbonated LDHs as an efficient adsorbent.

Although there have been extensive researches on the anion scavenging LDHs, to the best of our knowledge, there have been less interests in how the anions are removed by the LDHs and how the removal efficiency would be maximized. In addition, the elucidation of the adsorption or intercalation mechanisms by Monte Carlo simulations are scarce. Some examples for intercalation of antibiotics (cite here Zaher et al., 2020; 10.1007/s11356-020-07750-3 or Younes et al., 2019; 10.1016/j.jtice.2019.06.018) can be found in literature but only few articles deal with the use of simulations for dyes (cite Meng et al., 2019; 10.1016/j.clay.2019.01.012 and Aguiar et al., 2013; 10.1080/01496395.2013.804837). Meng et al., 2018; 10.1016/j.clay.2018.04.008 have already studied by Monte Carlo the methyl orange adsorption in $\mathrm{Zn}-\mathrm{Al}$ samples but in order to extract the energy of interaction.

We chose MO due as a model adsorbate due to the following reasons: i) MO is the representative azobased dyes which are widely utilized in industry, ii) chemistry of MO is well comprehended so that the mechanistic study of MO adsorption could be effectively carried out, and iii) there exist many references to compare adsorption. In this regard, our final goal is to elucidate MO adsorption on the LDHs with respect to physicochemical properties and to find a way to exploit all the possible adsorption sites of the carbonated LDHs. In this study, we hypothesized that effective usage of the interlayer nanospace is possible when a LDH with a smaller lateral size (small aspect ratio) is dispersed in a pollutant solution thanks to the accessibility to the interlayer nanospace. In order to achieve the efficient adsorption of MO, the carbonated LDH with the lateral diameter of $40 \mathrm{~nm}$ was synthesized by two titration steps to regulate a number of crystal nuclei and a nucleation rate. Other LDHs with different lateral sizes were also carefully synthesized to have well-defined physicochemical properties. Time dependent MO adsorption and isotherms with respect to particle dimension were obtained and analyzed by mathematical modelling to show the effective adsorption of MO onto the smaller sized LDHs. In addition, the Monte-Carlo simulation was carried out, to investigate the plausible adsorption sites upon MO intercalation and therefore to elucidate the conformation of the guest molecules in the LDH structure. The microscopic simulations indicate that $\pi$ - $\pi$ stacking stabilized MO in the interlayer nanospace and thus the stabilization is thought to be driving force of the MO adsorption through replacing even the carbonate anions. 
1

2

3

4

5

6

\section{Experimental}

\subsection{Materials}

Aluminum nitrate nonahydrate $\left(\mathrm{Al}\left(\mathrm{NO}_{3}\right)_{2} \cdot 9 \mathrm{H}_{2} \mathrm{O} ; 98 \%\right)$, urea $\left(\mathrm{CH}_{4} \mathrm{~N}_{2} \mathrm{O} ; 99.5 \%\right)$, methyl orange $\left(\mathrm{C}_{14} \mathrm{H}_{14} \mathrm{~N}_{3} \mathrm{NaO}_{3} \mathrm{~S} ; 85 \%\right)$ were purchased from Sigma-Aldrich Co. LLC, St. Louis., USA. Sodium hydroxide pellets $(\mathrm{NaOH} ; 97.0 \%)$ and sodium bicarbonate $\left(\mathrm{NaHCO}_{3} ; 99.7 \%\right)$ were obtained from Daejung Chemicals \& Metals Co., Ltd., Siheung, Korea. Magnesium nitrate hexahydrate $\left(\mathrm{Mg}\left(\mathrm{NO}_{3}\right)_{2} \cdot 6 \mathrm{H}_{2} \mathrm{O} ; 99.0 \%\right)$ was purchased from Junsei Chemical Co., Ltd., Tokyo, Japan. The deionized water was prepared from water purification system of Human power II+ (Human Corporation, Korea).

\subsection{Syntheses of size-controlled LDHs}

In order to obtain carbonated $\mathrm{MgAl}-\mathrm{LDH}$ with different lateral sizes, customized synthetic routes were applied. In order to obtain small size, a mixed metal solution $\left(0.3 \mathrm{~mol} \mathrm{~L}^{-1} \mathrm{Mg}^{2+}\right.$ and 0.15 mol L $\left.{ }^{-1} \mathrm{Al}^{3+}\right)$ was titrated with an alkaline solution $\left(0.12 \mathrm{~mol} \mathrm{~L}^{-1} \mathrm{NaOH}\right.$ and $\left.0.9 \mathrm{~mol} \mathrm{~L}^{-1} \mathrm{NaHCO}_{3}\right)$ until pH 9.5 for coprecipitation of both metal hydroxides. Especially, this process was carried out in two steps to produce small particles while preventing agglomeration among particles. The first step was fast titration until $\mathrm{pH} 7.0$ to form as many nuclei as possible; through this step, the nucleation could be limited and the size of LDH would be small. The second step was slow titration until $\mathrm{pH}$ 9.5 and following aging at room temperature for $24 \mathrm{~h}$. This process was expected to make particle surface smooth to reduce unintentional particle agglomeration. For the medium sized LDH, the metal solution was titrated by the alkaline solution until $\mathrm{pH} 9.5$ and was hydrothermally treated at $150{ }^{\circ} \mathrm{C}$ for $24 \mathrm{~h}$. For the largest LDH, urea hydrolysis method was applied; an aqueous solution $(0.375 \mathrm{~mol}$ $\mathrm{L}^{-1} \mathrm{Mg}^{2+}, 0.075 \mathrm{~mol} \mathrm{~L}^{-1} \mathrm{Al}^{3+}$ and $1.5 \mathrm{~mol} \mathrm{~L}-1$ urea) was mixed at $90^{\circ} \mathrm{C}$ for $48 \mathrm{~h}$ with vigorous stirring. All the white suspensions obtained from each reaction were centrifuged, thoroughly washed with deionized and lyophilized. Taking into account the lateral sizes of the LDHs, small, medium and large, the LDHs were designated as LDH-S, LDH-M and LDH-L, respectively.

\subsection{Powder X-ray diffraction (XRD)}

The crystallinity and crystal structure of the synthesized LDHs were evaluated by powder X-ray diffractometer (XRD) with a Bruker AXS D2 phaser (LYNXEYETM detector; Bruker AXS GmbH, Karlsruhe, Germany) using Ni-filtered $\mathrm{Cu}-\mathrm{K} \alpha$ radiation $(\lambda=1.5406 \AA$ ) with $1 \mathrm{~mm}$ of air-scattering slit and $0.1 \mathrm{~mm}$ of equatorial slit. XRD patterns were measured in a $2 \theta$ range from $5^{\circ}$ to $80^{\circ}$ with the time step increments of $0.02^{\circ}$ and a scanning rate of $0.5 \mathrm{~s} / \mathrm{step}$. Crystallite sizes of samples were calculated by Scherrer's equation as follows; $t=(0.9 \lambda) /(B \cdot \cos \theta)$ where $\lambda$ : X-ray wavelength, B: fullwidth-at-half-maximum, $\theta$ : Bragg angle). 


\subsection{Inductively coupled plasma-optical emission (ICP-OES)}

Compositions of metallic elements in the LDHs were analyzed by inductively coupled plasmaoptical emission spectrometer using plasma and spectrometer (ICP-OES; OPTIMA 7300DV, PerkinElmer). The powdered samples were thoroughly dissolved in hydrochloric acid and subsequently the solvent was evaporated on a hot plate. The remnants were added to $100 \mathrm{~mL}$ of deionized water and filtered with syringe filter (PVDF, $0.45 \mu \mathrm{m}, 13 \mathrm{~mm}$, Jaema Trade Inc.) for ICP measurement.

\subsection{Scanning electron microscopy (SEM)}

Morphologies and particle sizes of the LDHs were confirmed by scanning electron microscopy (SEM) using a Quanta 250 FEG (FEI Company, Hillsboro, OR, USA). For the SEM measurement, the samples were suspended in deionized water and then, the suspensions were dropped on a silicon wafer and dried in ambient conditions. The surface of the specimen was sputtered with Pt/Pd plasma for $60 \mathrm{~s}$, and the images were obtained using a $30 \mathrm{kV}$ accelerated electron beam.

\section{6. $\mathrm{N}_{2}$ gas adsorption-desorption isotherm}

$\mathrm{N}_{2}$ adsorption-desorption isotherms were obtained by Belsorp-mini (BEL, Japan, Inc, Osaka, Japan) after pre-treatment in vacuum for $12 \mathrm{~h}$ at $150{ }^{\circ} \mathrm{C}$ using BELPREP-vacII (BEL, Japan, Inc, Osaka, Japan). Specific surface areas of the LDHs were calculated according to the BrunauerEmmett-Teller (BET) theory and the porosities of the samples were estimated by Barret-JoynerHalenda (BJH) analysis method.

\subsection{Dynamic light scattering (DLS)}

Zeta potential values and hydrodynamic radii were obtained by electrophoretic light scattering and dynamic light scattering (DLS) using an ELS-Z1000 (Otsuka Electronics, Osaka, Japan). For electrophoretic light scattering measurement, the LDHs were dispersed in deionized water, where the $\mathrm{pH}$ value was adjusted to $\sim 8.4$ with $0.1 \mathrm{~mol} \mathrm{~L}^{-1} \mathrm{HCl}$ or $\mathrm{NaOH}$. The DLS measurement was done with the suspension without $\mathrm{pH}$ adjustment.

\subsection{Transmission Electron Microscopy (TEM)}

Cross-sectional morphologies and interlayer distances of the LDHs before and after adsorption of MO were determined by Field Emission Transmission Electron Microscope (FE-TEM; Titan G2 ChemiSTEM Cs probe, FEI company) operated at an accelerating voltage of $200 \mathrm{kV}$. TEM specimens for cross-sectional observation were prepared using Cryo Ultramicrotome (CUMT; PT PC Ultramicrotome \& Photographic). 


\subsection{Adsorption of methyl orange}

Time-dependent MO adsorption was observed at $7.0 \times 10^{-3} \mathrm{~mol} \mathrm{~L}^{-1} \mathrm{MO}$ solution. The LDHs were suspended in deionized water $\left(143 \mathrm{mg} 10 \mathrm{~mL}^{-1}\right)$ and added to $100 \mathrm{~mL}$ of the MO solution. Aliquots $(1 \mathrm{~mL})$ were collected at each time point until $48 \mathrm{~h}$ under stirring at room temperature, and then centrifuged and filtered by a syringe filter (PVDF, $0.45 \mu \mathrm{m}, 13 \mathrm{~mm}$, Jaema Trade Inc.). The adsorbed amount of MO was determined by quantifying un-adsorbed moiety in the supernatants and analyzed by using visible light spectroscopy (UV-1800, Shimadzu, Kyoto, Japan). The absorbance was measured at the wavelength of $464 \mathrm{~nm}$ which was an absorption peak of MO. The adsorbed amount, $Q_{t}(\mathrm{mg} / \mathrm{g}-\mathrm{LDH})$ was calculated as

$$
Q_{t}=\frac{V\left(C_{0}-C_{t}\right)}{W}
$$

$C_{0}$ and $C_{t}$ were concentrations at time 0 and $t$ of the $\mathrm{MO}$ solution $\left(\mathrm{mol} \mathrm{L}^{-1}\right), V$ was solution volume $(\mathrm{mL})$ and $W$ was mass of the absorbent $(\mathrm{g})$. The time dependent adsorption was fitted by pseudo-first order, pseudo-second order and Elovich equations.

The concentration dependent of MO adsorption on each LDH was carried out using the batch method. The LDHs were dispersed in deionized water $\left(10 \mathrm{mg} \mathrm{mL}^{-1}\right)$ and $1.5 \mathrm{~mL}$ of each suspension was mixed with $10 \mathrm{~mL} \mathrm{MO}$ solution with the concentration range of MO from $1.0 \times 10^{-5}$ to $1.5 \times 10^{-2}$ mol L $\mathrm{L}^{-1}$. The suspensions were shaken for $24 \mathrm{~h}$ with an orbital shaker and centrifuged at $3500 \mathrm{rpm}$ for $5 \mathrm{~min}$. The supernatant filtered with the syringe filter were analyzed by using UV-vis spectroscopy. The adsorption amount was calculated similarly. Obtained adsorption isotherms were analyzed by three models of the Langmuir, Freundlich, and Sips isotherms. The procedure was repeated three times.

\subsection{Monte-Carlo simulations}

In order to estimate the molecular configuration of MO in LDH interlayer space, MonteCarlo simulations were performed by using a home-made code. The molecular structure of MO was built, and the partial charges were calculated by density functional theory (DFT) calculation with $\mathrm{DMol}^{3}$. In this case, the geometry optimization was performed using GGA/PW91 functional, DNP basis set and all electrons are considered for the core treatment. The convergence tolerances for Energy, maximum force and maximum force variation were the following $10^{-5} \mathrm{Ha}, 0.02 \mathrm{Ha} / \AA, 0.005 \AA$ respectively (see Computational details in the Supporting Information).

Regarding LDH, the structure was taken from the methodology described the literature (Newman et al., 1998) and by adapting the chemical composition and the unit cell parameters to the ones obtained experimentally. Then the partial charges of the LDH structure were calculated by a electronegativity equalization method. The Lennard-Jones parameters were issued from universal force field (UFF). A multi-cell formed by $3 \times 3 \times 1$ unit cells for LDH was used for the Monte Carlo 
1 calculations in agreement with a cut-off for Lennard-Jones contributions fixed to $12.5 \AA$. The final 2 parameters corresponded thus at $\mathrm{a}=\mathrm{b}=27.414 \AA, \mathrm{c}=57 \AA, \alpha=\beta=90^{\circ}$ and $\chi=120^{\circ}$. The parameters of 3 the adsorbate/adsorbent Lonnard-Jones interatomic potential were then calculated using the Lorentz-

4 Berthelot combining rule. Concerning the long-range electrostatic interactions, the summation Ewald 5 technique was applied.

The simulations were performed in order to minimize the system energy by introducing a fixed number of anions in the structure. During these calculations, the motion of the anions included translation and rotation randomly considered during the equilibration steps. For that purpose, $10^{7}$

9 Monte Carlo production steps following $2 \times 10^{7}$ equilibration steps were performed at $300 \mathrm{~K}$ to extract the distribution of interlayer anions.

\section{Result and discussion}

\subsection{Characterization}

For systematic optimization, we would like to fix all the other parameters same except the size. Taking into account of a general chemical equation of LDHs $\left(\left[\mathrm{M}^{2+}{ }_{1-\mathrm{x}} \mathrm{M}^{3+}{ }_{\mathrm{x}}(\mathrm{OH})_{2}\right]^{\mathrm{x}}\left(\mathrm{A}^{\mathrm{n}-}{ }_{\mathrm{x} / \mathrm{n}}\right)^{\mathrm{X}-} \cdot \mathrm{mH}_{2} \mathrm{O}\right)$, chemical formulas were determined almost same for the three LDHs by ICP measurement: LDH-S $\left(\left[\mathrm{Mg}_{0.66} \mathrm{Al}_{0.34}(\mathrm{OH})_{2}\right]^{0.34+}\left(\mathrm{CO}_{3}{ }^{2-}{ }_{0.17}\right)^{0.34-} \cdot \mathrm{mH}_{2} \mathrm{O}\right)$, LDH-M $\left(\left[\mathrm{Mg}_{0.67} \mathrm{Al}_{0.33}(\mathrm{OH})_{2}\right]^{0.33+}\left(\mathrm{CO}_{3}{ }^{2-}{ }_{0.16}\right)^{0.33-} \cdot \mathrm{mH}_{2} \mathrm{O}\right)$ and LDH-L $\left(\left[\mathrm{Mg}_{0.66} \mathrm{Al}_{0.34}(\mathrm{OH})_{2}\right]^{0.34+}\left(\mathrm{CO}_{3}{ }^{2-}{ }_{0.17}\right)^{0.34-} \cdot \mathrm{mH}_{2} \mathrm{O}\right)$. Furthermore, we characterized the structural features such as phase, crystallinity and crystallite size of the LDHs. As shown in Fig. 1(a), all diffractograms had well-developed (003) and (006) peaks at the same position $11.7^{\circ}$ and $23.6^{\circ}$ along with several characteristic lattices peaks corresponding to hydrotalcite (JCPDS 14-0191) (San Román et al., 2008). The basal spacings of the LDHs were estimated to be $0.76 \mathrm{~nm}$, suggesting existence of interlayer carbonate anions. The lower intensity of the diffraction was observed in the smaller particle size. It indicates that the crystallinity of the LDHs decreased with the reduction in the particle size. We could also calculate the crystallite size along (003) plane to estimate the order of stacking along crystallographic c-axis. As summarized in Table 1, the crystallite sizes were 5.3, 42 and $36 \mathrm{~nm}$ for LDH-S, LDH-M, and LDH-L, respectively, showing that smaller particles tended to have less-ordered layer stacking. The XRD results confirmed that the prepared LDHs were same in crystal phase but different in crystallinity and crystallite size. 
(A)

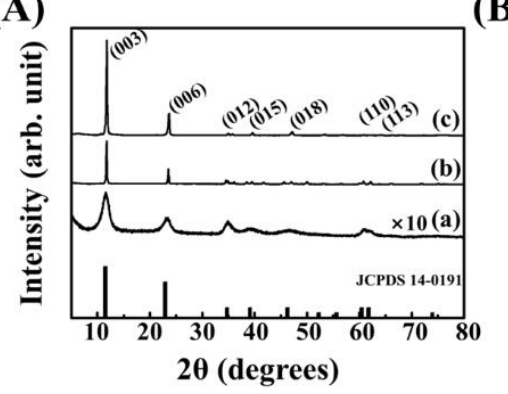

(B)

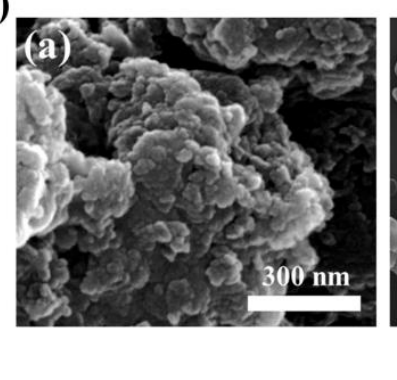

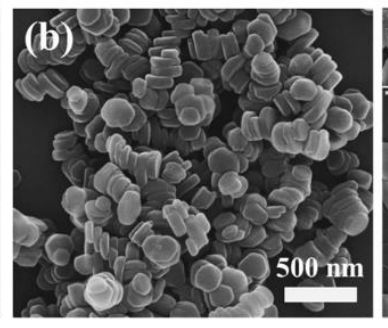

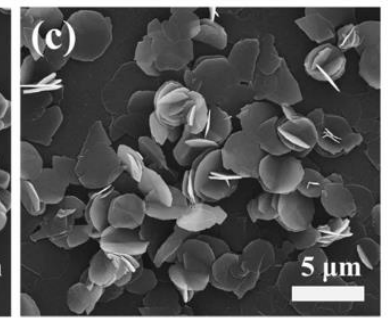

1

2 Fig. 1 (A) Powder X-ray diffraction (PXRD) patterns and (B) scanning electron microscopic 3 (SEM) images of (a) LDH-S, (b) LDH-M and (c) LDH-L. The XRD intensity for (a) was multiplied 4 by 10 for peak comparison. The vertical lines in the bottom of XRD patterns are the reference peak 5 from JCPDS 14-0191 (hydrotalcite) (San Román et al., 2008).

6

\begin{tabular}{|c|c|c|c|c|c|c|c|c|}
\hline \multirow[b]{2}{*}{ Sample } & \multicolumn{2}{|c|}{ XRD } & \multicolumn{2}{|l|}{ SEM } & \multicolumn{2}{|c|}{$\begin{array}{c}\mathrm{N}_{2} \text { adsorption- } \\
\text { desorption }\end{array}$} & \multicolumn{2}{|c|}{ Colloidal analysis } \\
\hline & $\begin{array}{c}\text { Crystalline } \\
\text { phase }\end{array}$ & $\begin{array}{l}\text { Crystallite } \\
\text { size }^{\mathrm{a}}(\mathrm{nm})\end{array}$ & $\begin{array}{c}\text { Lateral } \\
\text { dimension/thickness } \\
(\mathrm{nm} / \mathrm{nm})\end{array}$ & $\begin{array}{c}\mathrm{S}_{\mathrm{THE}} \\
\left(\mathrm{m}^{2} / \mathrm{g}\right)^{\mathrm{b}}\end{array}$ & $\begin{array}{l}\mathrm{S}_{\mathrm{BET}} \\
\left(\mathrm{m}^{2} / \mathrm{g}\right)\end{array}$ & $\begin{array}{c}\text { Total } \\
\text { pore } \\
\text { volume } \\
\left(\mathrm{cm}^{3} / \mathrm{g}\right)\end{array}$ & $\begin{array}{c}\text { Zeta } \\
\text { potential }\end{array}$ & $\begin{array}{c}\text { Hydrodynamic } \\
\text { radius }\end{array}$ \\
\hline LDH-S & & 5.3 & $40 / 40$ & 72.8 & 53.2 & 0.121 & 27.9 & 127.5 \\
\hline LDH-M & hydrotalcite & 42 & $190 / 68$ & 24.5 & 20.9 & 0.245 & 31.8 & 189.7 \\
\hline LDH-L & & 36 & $3000 / 100$ & 10.4 & 22.8 & 0.151 & 30.6 & 2863 \\
\hline
\end{tabular}

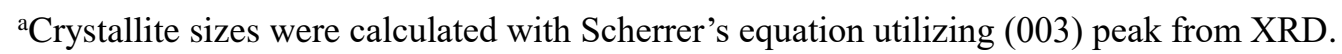

${ }^{b}$ Theoretical specific surface areas were determined by calculating surface area of one particle. Particle dimensions obtained from SEM were utilized to compute particle volume and area. Particle density $2.06 \mathrm{~g} / \mathrm{cm}^{3}$ of hydrotalcite $\left(\mathrm{Mg}_{3} \mathrm{Al}(\mathrm{OH})_{6}\left(\mathrm{CO}_{3}\right)_{0.5} \cdot 0.1 \mathrm{H}_{2} \mathrm{O}\right)$ was utilized to calculate particle mass.

\subsection{SEM}

The SEM images showed that the three LDHs were successfully synthesized to have different particle dimensions as intended (Fig. 1). As summarized in Table 1, the lateral size and thickness were clearly different in each other, especially the degree of the difference was more significant for lateral size showing 40, 190, and $3000 \mathrm{~nm}$ for LDH-S, LDH-M and LDH-L, respectively. Although the particles of LDH-S seemed to form agglomerates, we could distinguish the primary particle size of $40 \mathrm{~nm}$. As described in the experimental section, we especially made efforts in 
1 preparing LDH-S by controlling the nucleation rate and the edge smoothness. As reported previously, 2 controlling nucleus number and nucleation rate is critical in particle size control (Nývlt et al., 1985).

3 In addition, the edge of the particle become ordered through aging while the particle dimension was 4 generally preserved (Nývlt et al., 1985). Due to the customized synthesis control, LDH-S could avoid agglomeration among the particles, which were commonly found in small sized LDHs through edgeto-face interaction.(Clark et al., 2019; Jose et al., 2018) In order to estimate the homogeneity in the particle size, we obtained size distribution from randomly obtained 200 particles from the SEM images (Fig. S1 in supporting information). The results revealed that the particles were fairly homogeneous in the size, which was further verified in suspension states through dynamic light scattering (DLS).

\section{3. $\mathbf{N}_{2}$ adsorption-desorption isotherm}

As the surface area and pore structure are the determining parameters for adsorbent, we then carried out $\mathrm{N}_{2}$ adsorption-desorption isotherms onto the LDHs (Fig. S2 in supporting information). Both LDH-L and LDH-M showed Type III adsorption (weak adsorptive interaction), while LDH-S had some feature of Type IV adsorption (capillary condensation by mesopores) (Sing, 1985; Thommes et al., 2015). As it is obvious that the interlayer space of carbonated LDH does not serve as adsorption site for gases (Olfs et al., 2009), we could expect that the Type IV in LDH-S might be attributed to interparticle pores. As it was confirmed from the SEM that the primary particle diameter was $\sim 40$ $\mathrm{nm}$, we could geometrically expect the interparticle cavity of $\sim 10 \mathrm{~nm}$ which lays within the mesoporous range to induce the capillary condensation. In terms of the desorption branch, LDH-S showed the $\mathrm{H} 2$ type hysteresis (IUPAC classification) while LDH-M and LDH-L did not show it; the difference, similar to the adsorption pattern, was attributed to the different particle size. Nevertheless, we did not seriously consider the difference in the $\mathrm{N}_{2}$ adsorption-desorption patterns, as the adsorption of MO in aqueous suspensions would be more governed by specific surface area. The calculated $\mathrm{S}_{\mathrm{BET}}$ from the early stage of adsorption was 53.2, 20.9 and $22.8 \mathrm{~m}^{2} \mathrm{~g}^{-1}$ for LDH-S, LDH-M and LDH-L, respectively (Table 1). As the particle had only external surface as gas adsorption site, the difference in the particle size did not strikingly affect the specific surface area. As expected, the specific surface area was not significantly different in each other despite of the different $\mathrm{N}_{2}$ adsorption-desorption patterns. Furthermore, we calculated theoretical surface area $\left(\mathrm{S}_{\mathrm{THE}}\right)$ of the particles based on the size and density of the LDHs (Table 1). The theoretical value was fairly comparable with the experimental values, showing that most of the surface sites were exposed to adsorb molecules. From the $\mathrm{N}_{2}$ adsorption-desorption study, we could expect that LDH-S had slight advantage compared with the other two samples in terms of surface adsorption.

\subsection{DLS}

Although we confirmed the different primary particle sizes among the LDHs, we further 
1 characterized them in the aqueous state utilizing DLS (Fig. S3 in supporting information, Table 1) as our practical adsorption occurs in the water. The hydrodynamic size in the aqueous suspension showed average value of 128, 190 and $2863 \mathrm{~nm}$. It was worthy to note here that the hydrodynamic radius from DLS had comparable tendency with primary particle sizes from SEM. Moreover, taking into account the peak shape and width, the hydrodynamic radius was considered fairly homogeneous. We also checked the surface charge of the LDHs through zeta potential measurement, as the MO adsorption could be strongly affected by the charge-charge interactions between a sulfonate group of MO and positive LDH layer. We controlled the synthetic condition for the LDHs to have same composition and not to have any impurities; therefore the surface charge was successfully controlled same within $27.9-30.6 \mathrm{mV}$ in the same $\mathrm{pH}$ region.

According to the physicochemical characterizations, it was clearly confirmed that the three carbonated LDHs were prepared to have different properties in the particle size (both in powder and suspension) and crystallinity but comparable properties like crystalline phase, surface chemistry, pore structure and etc. Therefore, we proceeded the MO adsorption for the three LDHs in order to monitor the particle size effect on aqueous MO removal.

\subsection{Methyl orange (MO) adsorption}

For the first step, we investigated time-dependent $\mathrm{MO}$ adsorption at $7.0 \times 10^{-3} \mathrm{~mol} \mathrm{~L}^{-1}$ of an initial concentration. It was clearly shown that the adsorption of $\mathrm{MO}$ onto $\mathrm{LDH}-\mathrm{S}$ continued to 50 $\mathrm{h}$ while the adsorption onto LDH-M and LDH-L reached equilibrium within $4 \mathrm{~h}$ shown in Fig. 2. The MO adsorption kinetic was fitted to well-established model like pseudo-first order (eq. 2), pseudosecond order (eq. 3) and the Elovich equation (eq. 4) (Table 2).

$$
\begin{aligned}
& \ln \left(Q_{e}-Q_{t}\right)=\ln Q_{e}-k_{1} t \\
& \frac{t}{Q_{t}}=\left(\frac{t}{Q_{e}}\right)+\left(\frac{1}{k_{2} Q_{e}{ }^{2}}\right) \\
& Q_{t}=\left(\frac{1}{\beta}\right) \ln (\alpha \beta)+\left(\frac{1}{\beta}\right) \ln t
\end{aligned}
$$

( $Q_{e}$ : equilibrium adsorption amount of $\mathrm{MO}(\mathrm{mg} / \mathrm{g}-\mathrm{LDH}), Q_{t}$ : adsorbed amount (mg/g-LDH) at time $t$ (min), $k_{1}$ : pseudo-first order rate constant $\left(\mathrm{min}^{-1}\right), k_{2}$ : pseudo-second order rate constant $\left(\mathrm{g}(\mathrm{mg} \mathrm{min})^{-1}\right)$, $\alpha$ : initial adsorption rate $\left(\mathrm{g}(\mathrm{mg} \mathrm{min})^{-1}\right)$ and $\beta$ : Elovich constant $\left(\mathrm{g} \mathrm{mg}^{-1}\right)$.

As shown in Fig. S4 in supporting information, the kinetics were not sufficiently explained by pseudo-first order but explained well by pseudo-second order kinetics. We could compare the adsorption kinetics of the three LDHs utilizing pseudo-second order (Table 2). It was clearly shown that $Q_{e}$ of LDH-S was much larger (more than twice) than that of LDH-L, suggesting its excellent adsorption ability. The adsorption rate $k_{2}$ was following order: LDH-L $>$ LDH-M $>$ LDH-S. The 
1 kinetic constants represented that smaller particles required more time to be equilibrated, suggesting 2 that additional adsorption sites compared with LDH-M and LDH-L were activated in LDH-S. The 3 Elovich model showed anomalous fitting results with respect to the dimension of the LDHs. The $R^{2}$ 4 values obtained from the Elovich equation decreased with increase of the lateral dimension of the 5 LDHs. Although the Elovich equation is empirical and it was hard to conclude the meaning of the 6 fitting constants, the major hypothesis of this model - chemisorption and adsorption onto 7 heterogeneous surface (Ramachandran et al., 2011; Turner, 1975) - implied distinguishable adsorption 8 behavior of the small sized LDH compared with larger ones. In other words, the adsorption onto 9 LDH-S could include the chemisorption or adsorption onto heterogeneous surface while that onto 10 LDH-L preferred to the physisorption onto smooth surface. Possible explanation for the irreversible adsorption onto LDH-S is the electrostatic affinity of MO towards LDH layer and additional molecular attraction at the adsorbed state. Furthermore it can also be hypothesized that the global charge delocalization due to the substitution in the layer is weaker in the case of LDH-S than in LDH-L. This should lead to enhance the electrostatic effect towards the larger MO anions.

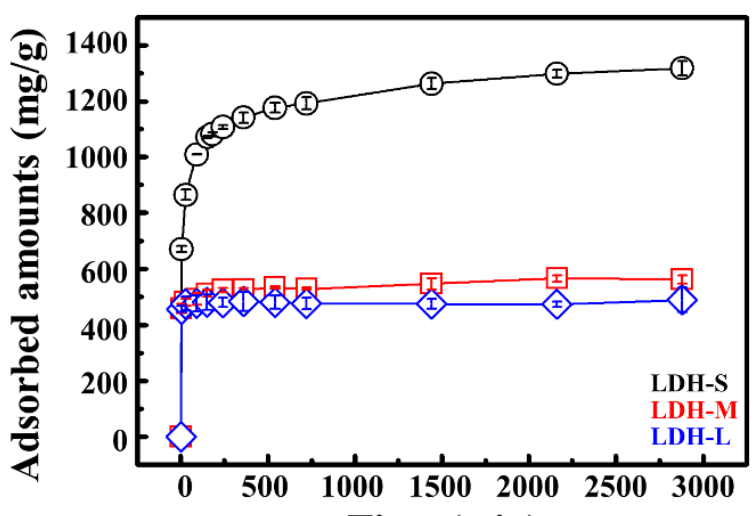

Time (min)

Fig. 2 Time-dependent MO adsorption onto the LDHs (-O-: LDH-S, - $\square-:$ LDH-M, - $\diamond$-: LDH-L) under ambient conditions with the initial concentration of $\mathrm{MO}$ of $7.0 \times 10^{-3} \mathrm{~mol} \mathrm{~L}^{-1}$.

Table 2. Kinetic parameters obtained from fitting with pseudo-first order, pseudo-second order and the Elovich equations.

\begin{tabular}{|c|c|c|c|c|c|c|c|c|c|}
\hline \multirow{2}{*}{ Adsorbent } & \multicolumn{3}{|c|}{$\begin{array}{l}\text { Pseudo-first order } \\
\text { equation }\end{array}$} & \multicolumn{3}{|c|}{$\begin{array}{l}\text { Pseudo-second order } \\
\text { equation }\end{array}$} & \multicolumn{3}{|c|}{ Elovich equation } \\
\hline & $\begin{array}{c}k_{1} \\
\left(\min ^{-1}\right)\end{array}$ & $\begin{array}{c}Q_{e} \\
(\mathrm{mg} / \mathrm{g})\end{array}$ & $R^{2}$ & $\begin{array}{c}k_{2}(\mathrm{~g}(\mathrm{mg} \\
\left.\min )^{-1}\right)\end{array}$ & $\begin{array}{c}Q_{e} \\
(\mathrm{mg} / \mathrm{g})\end{array}$ & $R^{2}$ & $\begin{array}{l}\alpha(\mathrm{g}(\mathrm{mg} \\
\left.\min )^{-1}\right)\end{array}$ & $\begin{array}{c}\beta(\mathrm{g} \\
\left.(\mathrm{mg})^{-1}\right)\end{array}$ & $R^{2}$ \\
\hline LDH-S & $1.4 \times 10^{-3}$ & 368.5 & 0.94 & $2.06 \times 10^{-5}$ & 1250 & 0.99 & $3.84 \times 10^{4}$ & 0.0105 & 0.99 \\
\hline
\end{tabular}




\begin{tabular}{cccccccccc} 
LDH-M & $1.0 \times 10^{-3}$ & 74.2 & 0.95 & $9.08 \times 10^{-5}$ & 555.6 & 0.99 & $7.38 \times 10^{12}$ & 0.062 & 0.96 \\
LDH-L & N.A. & N.A. & 0.007 & $4.37 \times 10^{-4}$ & 476.2 & 0.99 & N.A. & N.A. & 0.5 \\
\hline
\end{tabular}

1

2 As summarized in Table 2, the $Q_{e}$ of LDH-S (1250 mg/g-LDH) was larger than double of those of

3 LDH-M and LDH-L (555 and $476 \mathrm{mg} / \mathrm{g}-\mathrm{LDH}$, respectively). Despite of comparable hydrodynamic radius of LDH-S with LDH-M, it showed significantly increase in adsorption. This implied that the agglomeration of LDH-S was fairly negligible in terms of the MO adsorption and that LDH-S would have different $\mathrm{MO}$ adsorption mechanism compared with larger LDHs. The adsorbed amount at 150 min was converted to \%removal of MO showing 65, 31, and 30\% for LDH-S, LDH-M and LDHL, respectively. As shown in Fig. S3 in supporting information, the zeta potential of the LDHs was same. It indicated that the charge-charge interactions between MO and the LDHs were not the only reason of the larger adsorbed amount of MO onto LDH-S than the others. The adsorption amount of MO onto LDH-S was higher than that onto other materials (Table S1 in supporting information), expecting that LDH with small particle size is an excellent adsorbent of water pollution. Even the previously reported hybrid LDH adsorbent such as graphene-LDH (Zheng et al., 2019), carboxylateLDH (Zhu et al., 2014), $\mathrm{Fe}_{2} \mathrm{O}_{3}$-doped LDH (Cheng et al., 2019) and Cl-Co $4 \mathrm{Al}-\mathrm{LDH}$ (Chen et al., 2019) exhibited less adsorption amount (438, 476, 577 and $801 \mathrm{mg} / \mathrm{g}-\mathrm{LDH}$, respectively) than the LDH-S in current study.

\subsection{Adsorption isotherm}

Adsorption isotherms of MO onto the LDHs are shown in Fig. 3. The adsorbed amount (mg/g-LDH) of MO onto LDH-S was higher than those onto LDH-M and LDH-L in the equilibrium concentration from 0 to $0.010 \mathrm{~mol} \mathrm{~L}^{-1}$. Similarly, the adsorbed amount based on the surface area of sample $\left(\mathrm{mg} \mathrm{m}^{-2}\right)$ was higher in LDH-S than the others. The adsorption isotherms were analyzed by the Langmuir (eq. 5), Freundlich (eq. 6) equations and the Sips isotherm (eq. 7).

$$
\frac{1}{Q_{e}}=\frac{1}{Q_{\max } K C_{e}}+\frac{1}{Q_{\max }}
$$

$$
\log Q_{e}=\log K_{F}+\frac{1}{n} \log C_{e}
$$

$$
Q_{e}=\frac{Q_{\max } K_{S} C_{e}^{n}}{1+K_{S} C_{e}^{n}}
$$

( $Q_{\text {max }}$ : maximum amount of adsorbed MO (mg/g-LDH), $Q_{e}$ : adsorbed MO at equilibrium (mg/g-LDH), $C_{e}$ : concentration of $\mathrm{MO}$ at equilibrium $\left(\mathrm{mol} \mathrm{L}^{-1}\right), K$ : adsorption equilibrium constant $\left(\mathrm{L} \mathrm{mol}^{-1}\right), K_{F}$ : Freundlich adsorption capacity constant $\left(\mathrm{mg} \mathrm{g}^{-1} \mathrm{~L}^{\mathrm{n}} \mathrm{mol}^{-\mathrm{n}}\right), K_{S}$ : Sips equilibrium constant $\left(\mathrm{L}^{\mathrm{n}} \mathrm{mol}^{-\mathrm{n}}\right)$ and $n$ : related value to the adsorption intensity with heterogeneity of the LDHs) 

with the Langmuir and Sips equations in the three LDHs as shown in Fig. S5 in supporting information and as summarized in Table 3. The Freundlich model allows the multilayer adsorption, whereas the Langmuir and Sips equations are based on monolayer adsorption (Tzabar and ter Brake, 2016). The molecular dimension of MO estimated from single crystal X-ray crystallography is a cylinder with 1.5 $\mathrm{nm}$ length and $0.5 \mathrm{~nm}$ diameter (Burke et al., 2004). The molecular density of the adsorbed MO on the LDH-S was estimated to be larger than 40 molecules $\mathrm{nm}^{-2}$ from $\mathrm{S}_{\mathrm{BET}}$. Taking into account the two aspects, it is strongly suggested that the MO molecules existed in aggregates (Grégoire et al., 2019) or they were intercalated into the interlayer space (Neumann et al., 2002).

(a)

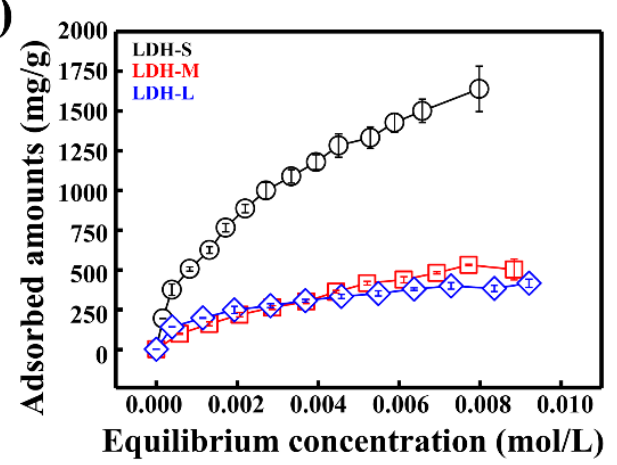

(b)

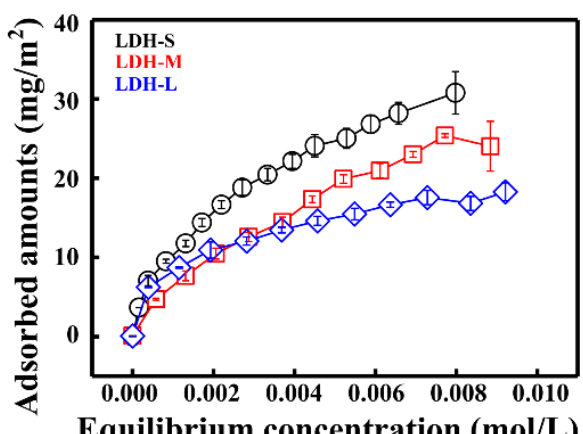

Fig. 3 Methyl orange adsorption isotherms (a) adsorbed amount was determined based on mg$\mathrm{MO} / \mathrm{g}-\mathrm{LDH}$ (b) adsorbed amount was determined based on mg-MO per surface area $\left(\mathrm{m}^{2}\right)$ of LDH. (-

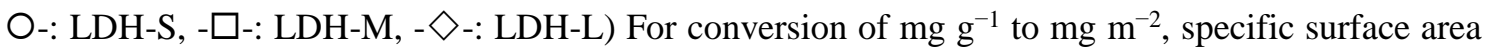
values obtained from $\mathrm{N}_{2}$ adsorption-desorption isotherm were utilized.

Table 3. Isotherm parameters of MO adsorption on $\mathrm{LDH}$ adsorbent based on various adsorption models

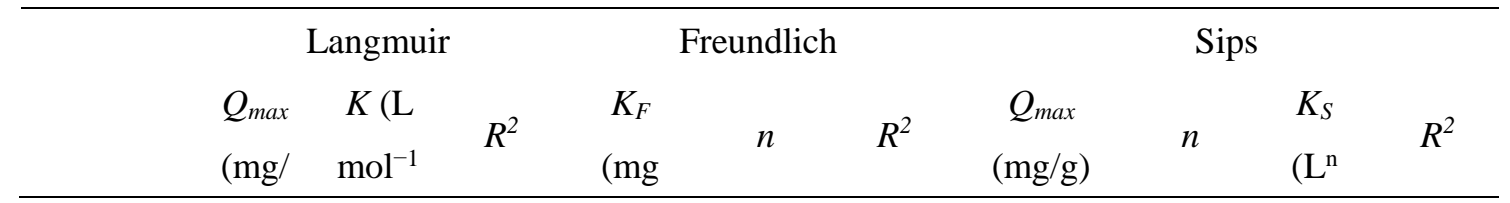




\begin{tabular}{ccccccccccc} 
& $\mathrm{g})$ & ) & \multicolumn{3}{c}{$\mathrm{g}^{-1} \mathrm{~L}^{\mathrm{n}}$} \\
$\left.\mathrm{mol}^{-\mathrm{n}}\right)$
\end{tabular}

1

$2 \quad$ 3.7. Transmission electron microscopy (TEM)

3

4 LDH-S replacing pre-existing carbonate anion. In order to detect the intercalation directly, high-

5 resolution cross-section TEM was carried out (Fig. 4). The TEM image of LDH-S showed assembly

6 of lamellar structure of which interlayer distance was estimated to be $0.76 \mathrm{~nm}$ (Fig. 4a), which was

7 comparable to the PXRD pattern (Fig. 1). Although the morphology of LDH-S was not largely

8 changed as shown in Fig. S9 in supporting information (El Hassani et al., 2017; Zhu et al., 2014), the

9 adsorption of MO increased the interlayer distance to $1.9 \mathrm{~nm}$ (Fig. 4a), strongly indicating the

10 intercalation of MO into the interlayer space despite of the stability of the interlayer carbonate anions

11 (Miyata, 1983). New diffraction peak at $4.6^{\circ}$ after the MO adsorption on LDH-S corresponded to the

12 basal spacing of $1.92 \mathrm{~nm}$ in PXRD, corroborating the adsorption of MO even in the interlayer space

13 of LDH-S (Fig. 5a). In case of LDH-M, three interlayer distances of 0.76, 0.93 and $1.9 \mathrm{~nm}$ were

14 observed in the TEM image (Fig. 5b), suggesting that the MO was partially intercalated into the

15 interlayer space. The PXRD pattern of LDH-M adsorbed MO showed both diffraction peaks at $4.6^{\circ}$

16 and $11.7^{\circ}$, which supported the observation of TEM. The change of the interlayer distance of LDH-

17 L was not observed by TEM after the adsorption of MO, while the relatively small but definite

18 diffraction peak attributed to the LDH intercalated MO was observed at $4.6^{\circ}$ in PXRD (Fig. 5c). 
(a)
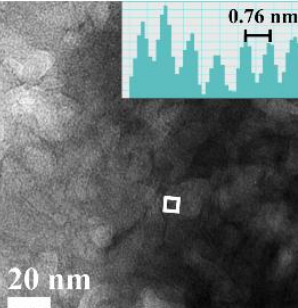

(b)

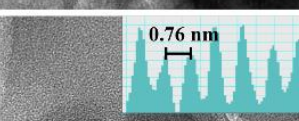

(c)

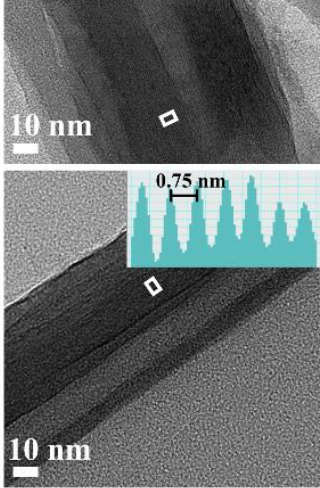

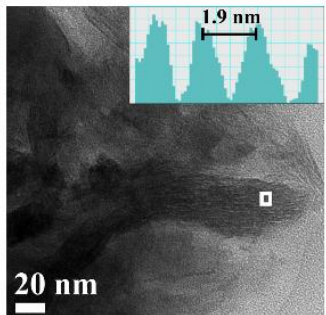

$20 \mathrm{~nm}$
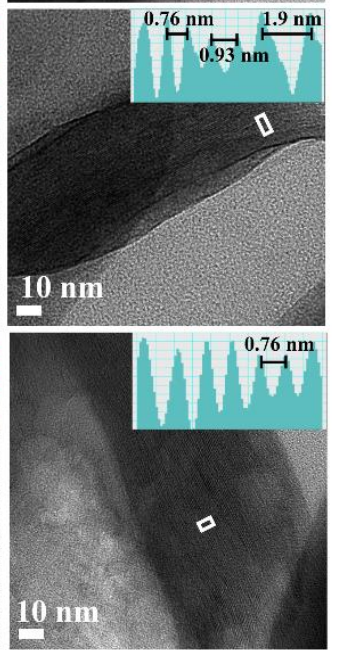

2 Fig. 4 Transmission electron microscopic (TEM) images for (a) LDH-S, (b) LDH-M and (c) LDH-

3 L before (left panels) and after (right panels) MO adsorption. The interlayer distance was visualized

4 by the inset histograms obtained in the white rectangle region.

5 
(a)

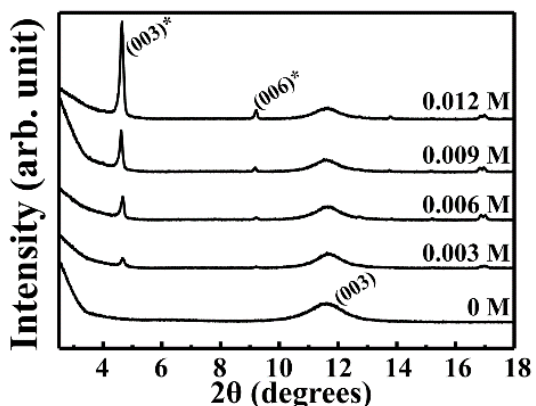

(b)

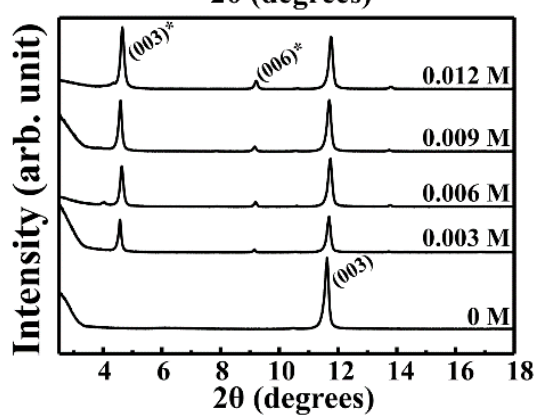

(c)

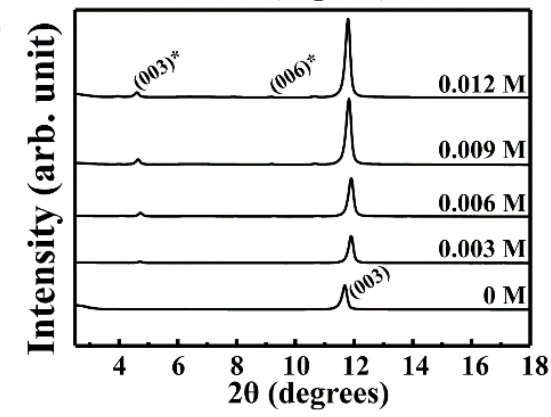

1

2 Fig. 5 X-ray diffraction patterns of (a) LDH-S, (b) LDH-M and (c) LDH-L before and after MO 3 adsorption at various MO concentration. The concentration indicates the initial concentration of MO 4 before adsorption.

5

6

\subsection{Monte-Carlo simulation}

In order to speculate the geometry of MO in the LDHs and to address distinct MO intercalation behavior in a small sized carbonated LDH, the Monte-Carlo simulation was performed (see experimental section in the detail). The first step consisted to estimate the maximum MO amount that the interlayer space can accommodate by imposing the layer-layer distance obtained experimentally $\left(\mathrm{d}_{003}\right)$. It followed from the calculations that $41 \mathrm{MO}$ anions could enter in the interlayer space due to the steric repulsion and $20 \mathrm{CO}_{3}{ }^{2-}$ were required to obtain a neutral charge in the multi-cell considered in our calculations. This theoretical maximum loading corresponded to a MO mass of around $1000 \mathrm{mg} / \mathrm{g}$ dry LDH. In comparison with the experimental results (see Fig. 3), in LDH-M and LDH-L, $\mathrm{CO}_{3}{ }^{2-}$ were not totally exchanged by MO while LDH-S was completely exchanged in the interlayer space and probably a non-negligible part of MO was also adsorbed on the 
1 external surface. As shown in Fig. $6 \mathrm{a}$ and $6 \mathrm{~b}, \mathrm{CO}_{3}{ }^{2-}$ were in strong interactions with the $\mathrm{LDH}$ layer 2 through the three $\mathrm{O}$ but without interaction with other ions ( $\mathrm{MO}$ or other $\mathrm{CO}_{3}{ }^{2-}$ ), while $\mathrm{MO}$ anions 3 could be closely packed in the interlayer space of the LDH taking advantage of nanoconfinement. If $4 \mathrm{MO}$ anions are located in the interlayer space of the LDH, its sulfonate group heads for the LDH layers and strongly interacts with the $\mathrm{OH}$ groups closed to substitutions. Various arrangements of the anions are obtained from the calculations illustrating that the anions are not strictly perpendicular to the layers but are tilted as observed in the case of amines in layered solids (Alby et al., 2018). Different configurations are reported in Fig. 6b. Such configurations are mainly due to the size of the MO ion (14.5 $\AA$ ) compared to the interlayer space $(19.2 \AA)$ and taking into account of the size of the LDH layer $(\sim 4 \AA)$ and to the intermolecular interactions. Fig. $6 \mathrm{c}$ and $6 \mathrm{~d}$ clearly describe that the strong $\pi$ $\pi$ stacking between MO molecules adsorbed in the interlayer space was possible when the intermolecular distance is $\sim 3.4-3.7 \AA$, following a sandwich configuration, where the benzene rings were parallel and could interact directly together.

It is generally accepted in clay intercalation chemistry that ionic moiety first interact with the surface of clay layers (Neumann et al., 2002; Valandro et al., 2015), and then the ions at the edge of the clay particle gradually migrate into the interlayer space through concentration gradient. Similarly, the MO molecules first attached on the surface, and the molecules at the periphery of the particle would have a chance to move into gallery (Fig. 7 top sides). At this stage, usual carbonated $\mathrm{LDH}$ overcome the invasion of $\mathrm{MO}$ as the adsorption enthalpy calculated at the anhydrous state for carbonate $(284 \mathrm{kcal} / \mathrm{mol})$ is much larger than that determined for $\mathrm{MO}(122 \mathrm{kcal} / \mathrm{mol})$. However, the impact of hydration shows clearly that the $\mathrm{CO}_{3}{ }^{2-}$ can interact with water while $\mathrm{MO}$ acts as an inhibitor of the hydration due to the strong hydrophobic character of this anion. Furthermore, LDH-S with the small lateral dimension is expected to provide short edge circumference for the MO moiety to easily get $\pi-\pi$ stabilization ( $110 \mathrm{kcal} / \mathrm{mol}$ ), giving rise to nanoconfinement (Fig. 7a). In large particles, due to the long circumference, there may not be appropriate formation of a band of $\mathrm{MO}$ at the edge to get efficient $\pi-\pi$ interaction (Fig. $7 b$ ). In this way, small particles would provide a more chance for MO to get additional stabilization; as a consequence, electrostatic interaction and $\pi-\pi$ attraction of MO overcome the stability of carbonate to be intercalated in LDH-S. On the other hand, due to the stability of the adsorbed MO, the regeneration of LDH-S might be lower than the other LDH-based adsorbent like previous report (Gwak et al., 2016). 

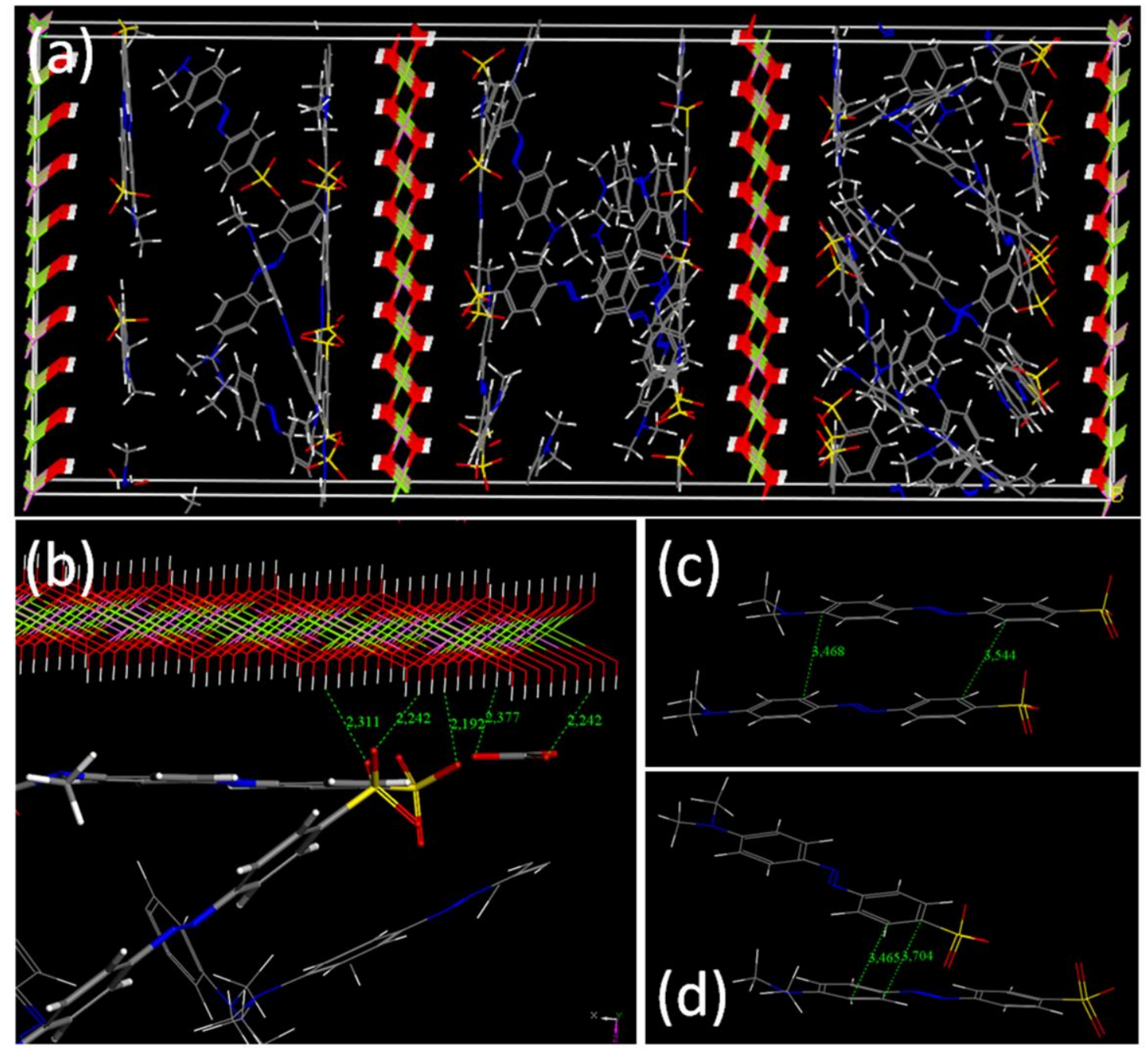

2 Fig. 6 (a) Global snapshot of the structure of MO containing LDH, (b) snapshot of the interactions 3 for both $\mathrm{MO} \mathrm{CO}_{3}{ }^{2-}$ and $\mathrm{LDH}$ layer (also showing the orientation of the intercalated $\mathrm{MO}$ ), and (c and 4 d) $\pi-\pi$ stacking of MO in LDH simulated by Monte-Carlo method. The details of the simulation were 5 mentioned in experimental section. 
(a) Small particle

(b) Large particle

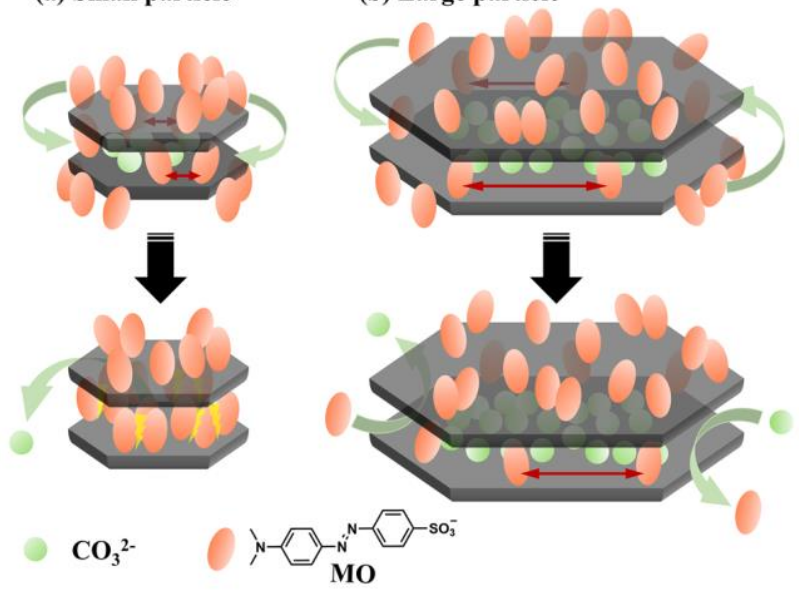

Fig. 7 Schematic diagram to explain different nanoconfinement effect of methyl orange upon adsorption on (a) small and (b) large LDH particles

4

5

\section{Conclusion}

Efficient removal of MO was achieved in a small-sized and non-agglomerated LDH (LDH-

S) The adsorption amount of LDH-S was as high as $1250 \mathrm{mg} / \mathrm{g}-\mathrm{LDH}$, which was much larger than other reported adsorbent as well as larger sized LDH. The analyses of the adsorption kinetics suggested that MO was removed mainly by the anion exchange mechanism; especially, LDH-S filled its interlayer space with MO moiety through effective $\pi-\pi$ stacking which was revealed by TEM, XRD and Monte-Carlo simulation. We could conclude that this unusual interlayer utility of the carbonated LDH was possible with small lateral sizes $\sim 40 \mathrm{~nm}$. At the best of our knowledge, carbonated LDH with $\sim 40 \mathrm{~nm}$ of lateral dimension is one of the best candidates to remove the water pollutant with environmentally, and economically friendly characters. As future perspective, easy removal of dyes by LDHs with magnetic field and effective photocatalytic reactions are expected by hybridization with metal nanoparticles.

\section{CRediT authorship contribution statement}

Su-Joung Ko: Methodology, Validation, Tetsuo Yamaguchi : Writing-Original Draft, Fabrice Salles : Software, Writing - Review \& Editing, Jae-Min Oh : Conceptuation, Supervision

\section{Conflicts of interest}

There are no conflicts to declare.

\section{Acknowledgement}

This work was supported by Radiation Technology R\&D program through the National Research 
1 Foundation of Korea funded by the Ministry of Science and ICT(2017M2A2A6A05016600,

2 2017M2A2A6A05093711)

3

4

5

6

\section{References}

Alby, D., Jeaidi, N. El, Salles, F., Zajac, J., Charnay, C., 2018. In fluence of the templating amine on the nanostructure and charge of layered vanadates for radioactive wastewater treatment. ACS Appl. Nano Mater. 2, 497-504. https://doi.org/10.1021/acsanm.8b02058

Atun, G., Tunçay, M., Hisarli, G., Talman, R.Y., Hoşgörmez, H., 2009. Adsorption equilibria between dye and surfactant in single and binary systems onto geological materials. Appl. Clay Sci. 45, 254261. https://doi.org/10.1016/j.clay.2009.06.003

Aznar, E., Oroval, M., Pascual, L., Murguía, J.R., Martínez-Mánez, R., Sancenón, F., 2016. Gated Materials for On-Command Release of Guest Molecules. Chem. Rev. 116, 561-718. https://doi.org/10.1021/acs.chemrev.5b00456

Bée, A., Obeid, L., Mbolantenaina, R., Welschbillig, M., Talbot, D., 2017. Magnetic chitosan/clay beads: A magsorbent for the removal of cationic dye from water. J. Magn. Magn. Mater. 421, 59-64. https://doi.org/10.1016/j.jmmm.2016.07.022

Burke, N.J., Burrows, A.D., Mahon, M.F., Teat, S.J., 2004. Incorporation of sulfonate dyes into hydrogen-bonded networks. CrystEngComm 6, 429-436. https://doi.org/10.1039/b406614f

Chen, Y., Jing, C., Zhang, X., Jiang, D., Liu, X., Dong, B., Feng, L., Li, S., Zhang, Y., 2019. Acid-salt treated CoAl layered double hydroxide nanosheets with enhanced adsorption capacity of methyl orange dye. J. Colloid Interface Sci. 548, 100-109. https://doi.org/10.1016/j.jcis.2019.03.107

Cheng, S., Shao, L., Ma, J., Xia, X., Liu, Y., Yang, Z., Yang, C., Li, S., 2019. Simultaneous removal of phosphates and dyes by double hydroxide nanoflakes. Environ. Sci. Nano 6, 2615-2625. https://doi.org/10.1039/c9en00520j

Choy, J.H., Choi, S.J., Oh, J.M., Park, T., 2007. Clay minerals and layered double hydroxides for novel biological applications. Appl. Clay Sci. 36, 122-132. https://doi.org/10.1016/j.clay.2006.07.007

Clark, I., Gomes, R.L., Crawshaw, C., Neve, L., Lodge, R., Fay, M., Winkler, C., Hulle, M., Lester, E., 2019. Continuous synthesis of Zn2Al-CO3 layered double hydroxides: a comparison of bench, pilot and industrial scale syntheses. React. Chem. Eng. 663-666. https://doi.org/10.1039/C8RE00241J

Delkash, M., Ebrazi Bakhshayesh, B., Kazemian, H., 2015. Using zeolitic adsorbents to cleanup special wastewater streams: A review. Microporous Mesoporous Mater. 214, 224-241. https://doi.org/10.1016/j.micromeso.2015.04.039

El Hassani, K., Beakou, B.H., Kalnina, D., Oukani, E., Anouar, A., 2017. Effect of morphological properties of layered double hydroxides on adsorption of azo dye Methyl Orange: A comparative study. Appl. Clay Sci. 140, 124-131. https://doi.org/10.1016/j.clay.2017.02.010 
Goh, K., Lim, T., Dong, Z., 2008. Application of layered double hydroxides for removal of oxyanions : A review. Water Res. 42, 1343-1368. https://doi.org/10.1016/j.watres.2007.10.043

Gomez, I.J., Arnaiz, B., Cacioppo, M., Arcudi, F., Prato, M., 2018. Nitrogen-doped Carbon Nanodots for bioimaging and delivery of paclitaxel. J. Mater. Chem. B 6. https://doi.org/10.1039/x0xx00000x

Grégoire, B., Bantignies, J.L., Le-Parc, R., Prélot, B., Zajac, J., Layrac, G., Tichit, D., Martin-Gassin, G., 2019. Multiscale mechanistic study of the adsorption of methyl orange on the external surface of layered double hydroxide. J. Phys. Chem. C 123, 22212-22220. https://doi.org/10.1021/acs.jpcc.9b04705

Gwak, G.-H., Kim, M.-K., Oh, J.-M., 2016. Nanocomposites of magnetite and layered double hydroxide for recyclable chromate removal. J. Nanomater. 2016, 1-10. https://doi.org/10.1155/2016/8032615

He, H., Kang, H., Ma, S., Bai, Y., Yang, X., 2010. High adsorption selectivity of ZnAl layered double hydroxides and the calcined materials toward phosphate. J. Colloid Interface Sci. 343, 225-231. https://doi.org/10.1016/j.jcis.2009.11.004

Jose, N.A., Zeng, H.C., Lapkin, A.A., 2018. Hydrodynamic assembly of two-dimensional layered double hydroxide nanostructures. Nat. Commun. 4913. https://doi.org/10.1038/s41467-018-07395-4

Khan, N.A., Hasan, Z., Jhung, S.H., 2013. Adsorptive removal of hazardous materials using metalorganic frameworks (MOFs): A review. J. Hazard. Mater. 244-245, 444-456. https://doi.org/10.1016/j.jhazmat.2012.11.011

Kim, T.-H., Hong, I.-T., Lee, J.-Y., Kang, J.-H., Oh, J.-M., 2014. Layered nanomaterials for environmental remediation applications. Energy Environ. Focus 3, 23-36. https://doi.org/10.1166/eef.2014.1087

Leodopoulos, C., Doulia, D., Gimouhopoulos, K., 2014. Adsorption of Cationic Dyes onto Bentonite. Sep. Purif. Rev. 44, 74-107. https://doi.org/10.1080/15422119.2013.823622

Leroux, F., Taviot-Gueho, C., 2005. Fine tuning between organic and inorganic host structure: new trends in layered double hydroxide hybrid assemblies. J. Mater. Chem. 15, 3628-3642. https://doi.org/10.1039/b505014f

Li, S.S., Jiang, M., Jiang, T.J., Liu, J.H., Guo, Z., Huang, X.J., 2017. Competitive adsorption behavior toward metal ions on nano-Fe/Mg/Ni ternary layered double hydroxide proved by XPS: Evidence of selective and sensitive detection of $\mathrm{Pb}(\mathrm{II})$. J. Hazard. Mater. 338, 1-10. https://doi.org/10.1016/j.jhazmat.2017.05.017

Liu, P., Zhang, L., 2007. Adsorption of Dyes from Aqueous Solutions or Suspensions with Clay NanoAdsorbents. Sep. Purif. Technol. 58, 32-39. https://doi.org/10.1016/j.seppur.2007.07.007

Malamis, S., Katsou, E., 2013. A review on zinc and nickel adsorption on natural and modified zeolite, bentonite and vermiculite: Examination of process parameters, kinetics and isotherms. J. Hazard. Mater. 252-253, 428-461. https://doi.org/10.1016/j.jhazmat.2013.03.024

Miyata, S., 1983. Anion-exchange properties of hydrotalcite-like compounds. Clays Clay Miner. 31, 305- 
Mohanty, K., Jha, M., Meikap, B.C., Biswas, M.N., 2006a. Biosorption of Cr(VI) from aqueous solutions by Eichhornia crassipes. Chem. Eng. J. 117, 71-77. https://doi.org/10.1016/j.cej.2005.11.018

Mohanty, K., Naidu, J.T., Meikap, B.C., Biswas, M.N., 2006b. Removal of crystal violet from wastewater by activated carbons prepared from rice husk. Ind. Eng. Chem. Res. 45, 5165-5171.

Neumann, M.G., Gessner, F., Schmitt, C.C., Sartori, R., 2002. Influence of the layer charge and clay particle size on the interactions between the cationic dye methylene blue and clays in an aqueous suspension. J. Colloid Interface Sci. 255, 254-259. https://doi.org/10.1006/jcis.2002.8654

Newman, S.P., Williams, S.J., Coveney, P. V., Jones, W., 1998. Interlayer arrangement of hydrated MgAl layered double hydroxides containing guest terephthalate anions: Comparison of simulation and measurement. J. Phys. Chem. B 102, 6710-6719.

Nývlt, J., Söhnel, O., Matuchová, M., Broul, M., 1985. The Kinetics of Industrial Crystallization. Elsevier, Amsterdam.

Oh, J.M., Biswick, T.T., Choy, J.H., 2009. Layered nanomaterials for green materials. J. Mater. Chem. 19, 2553-2563. https://doi.org/10.1039/b819094a

Olfs, H.W., Torres-Dorante, L.O., Eckelt, R., Kosslick, H., 2009. Comparison of different synthesis routes for $\mathrm{Mg}-\mathrm{Al}$ layered double hydroxides $(\mathrm{LDH})$ : Characterization of the structural phases and anion exchange properties. Appl. Clay Sci. 43, 459-464. https://doi.org/10.1016/j.clay.2008.10.009

Omwoma, S., Chen, W., Tsunashima, R., Song, Y.F., 2014. Recent advances on polyoxometalates intercalated layered double hydroxides: From synthetic approaches to functional material applications. Coord. Chem. Rev. 258-259, 58-71. https://doi.org/10.1016/j.ccr.2013.08.039

Phuekphong, A. (Fern), Imwiset, K. (Jaa), Ogawa, M., 2020. Designing nanoarchitecture for environmental remediation based on the clay minerals as building block. J. Hazard. Mater. 399, 122888. https://doi.org/10.1016/j.jhazmat.2020.122888

Pilavtepe, M., Dela Vernhe, L., Steudel, A., Schuhmann, R., Willenbacher, N., Emmerich, K., 2018. Formation of arrested states in natural di-and trioctahedral smectite dispersions compared to those in synthetic hectorite - A macro-and microrheological study. Clays Clay Miner. 66, 339-352. https://doi.org/10.1346/CCMN.2018.064102

Ramachandran, P., Vairamuthu, R., Ponnusamy, S., 2011. Adsorption isotherms, kinetics, thermodynamics and desorption studies of reactive orange 16 on activated carbon derived from Ananas comosus (L.) carbon. J. Eng. Appl. Sci. 6, 15-26.

Rives, V. (Ed.), 2001. Layered double hydroxides: present and future. Nova Science Publishers, Inc., New York.

San Román, M.S., Holgado, M.J., Jaubertie, C., Rives, V., 2008. Synthesis, characterisation and delamination behaviour of lactate-intercalated $\mathrm{Mg}$,Al-hydrotalcite-like compounds. Solid State Sci. 
10, 1333-1341. https://doi.org/10.1016/j.solidstatesciences.2008.01.026

Sing, K.S.W., 1985. Reporting physisorption data for gas/solid systems with special reference to the determination of surface area and porosity. Pure Appl. Chem. 57, 603-619. https://doi.org/10.1351/pac198557040603

Smith, J.A., Jaffé, P.R., 1994. Adsorptive selectivity of organic-cation-modified bentonite for nonionic organic contaminants. Water, Air, Soil Pollut. Vol. 72, 205-211.

Srividya, K., Mohanty, K., 2009. Biosorption of hexavalent chromium from aqueous solutions by Catla catla scales: Equilibrium and kinetics studies. Chem. Eng. J. 155, 666-673. https://doi.org/10.1016/j.cej.2009.08.024

Sun, Z., Deng, Y., Wei, J., Gu, D., Tu, B., Zhao, D., 2011. Hierarchically ordered macro-/mesoporous silica monolith: Tuning macropore entrance size for size-selective adsorption of proteins. Chem. Mater. 23, 2176-2184. https://doi.org/10.1021/cm103704s

Teepakakorn, A.P., Yamaguchi, T., Ogawa, M., 2019. The Improved Stability of Molecular Guests by the Confinement into Nanospaces. Chem. Lett. 48, 398-409. https://doi.org/10.1246/cl.181026

Thommes, M., Kaneko, K., Neimark, A. V., Olivier, J.P., Rodriguez-Reinoso, F., Rouquerol, J., Sing, K.S.W., 2015. Physisorption of gases, with special reference to the evaluation of surface area and pore size distribution (IUPAC Technical Report). Pure Appl. Chem. 87, 1051-1069. https://doi.org/10.1515/pac-2014-1117

Turner, N.H., 1975. Kinetics of chemisorption: An examination of the Elovich equation. J. Catal. 36, 262-265. https://doi.org/10.1016/0021-9517(75)90035-4

Tzabar, N., ter Brake, H.J.M., 2016. Adsorption isotherms and Sips models of nitrogen, methane, ethane, and propane on commercial activated carbons and polyvinylidene chloride. Adsorption 22, 901914. https://doi.org/10.1007/s10450-016-9794-9

Valandro, S.R., Poli, A.L., Neumann, M.G., Schmitt, C.C., 2015. Photophysics of auramine O adsorbed on solid clays. J. Lumin. 161, 209-213. https://doi.org/10.1016/j.jlumin.2015.01.023

Wang, Q., Hare, D.O., 2012. Recent advances in the synthesis and application of layered double hydroxide (LDH) nanosheets. Chem. Rev. 112, 4124-4155. https://doi.org/10.1021/cr200434v

Wijitwongwan, R.P., Intasa-ard, S.G., Ogawa, M., 2019. Preparation of layered double hydroxides toward precisely designed hierarchical organization. Chem. Eng. 3, 68. https://doi.org/10.3390/chemengineering3030068

Yamaguchi, T., Ogawa, M., 2020. Photochromic Reactions in Nanospace; Host-Guest Interactions and Opportunity, in: Douhal, A., Anpo, M. (Eds.), Dyes and Photoactive Molecules in Microporous Systems. Elsevier, Amsterdam, pp. 163-177.

Zhang, X., Gao, B., Creamer, A.E., Cao, C., Li, Y., 2017. Adsorption of VOCs onto engineered carbon materials: A review. J. Hazard. Mater. 338, 102-123. https://doi.org/10.1016/j.jhazmat.2017.05.013

Zheng, Y., Cheng, B., You, W., Yu, J., Ho, W., 2019. 3D hierarchical graphene oxide-NiFe LDH 
composite with enhanced adsorption affinity to Congo red, methyl orange and $\mathrm{Cr}(\mathrm{VI})$ ions. J.

2 Hazard. Mater. 369, 214-225. https://doi.org/10.1016/j.jhazmat.2019.02.013

Zhu, S., Jiao, S., Liu, Z., Pang, G., Feng, S., 2014. High adsorption capacity for dye removal by CuZn hydroxyl double salts. Environ. Sci. Nano 1, 172-180. https://doi.org/10.1039/C3EN00078H 